\title{
Thyroid autoimmunity in adverse fertility and pregnancy outcomes: Timing of assisted reproductive technology in AITD women
}

\author{
Jia-Wei Wang ${ }^{1}$ Xiao-Xian Liao' ${ }^{2}$ Tuo $\mathrm{Li}^{2}$ \\ 'Department of Obstetrics and Gynecology, Nantong Maternity and Child Health Care Hospital \\ affiliated to Nantong University, Nantong 226018, Jiangsu Province, China; \\ 2Department of endocrinology, Changzheng hospital, Naval Medical University, Shanghai 200003, China
}

\section{ABSTRACT}

Thyroid autoimmunity (TAl) is prevalent in women of live-birthing age and has independently been associated with complications of fertility and pregnancy, in the case of spontaneous conception or after assisted reproductive technology (ART) treatment. However, it remains challenging to identify causation between infertility and TAI, even interventional trials looking at the impact of levothyroxine (LT4) treatment on fertility and pregnancy outcomes due to differences among study results which related to small scales, impropriate study designs, enrollment criteria of infertility cause and titer/hormone concentration measurements. Furthermore, many questions remain unsettled in ART management in AITD infertile women attempt pregnancy. Therefore, further observational and interventional trials are needed more comprehensive multiple-center, double blinded, and randomized.

Key words: autoimmune thyroid diseases, AITD, Infertility, Assisted reproductive technology, ART

\section{INTRODUCTION}

Autoimmune thyroid diseases, AITD, are the most common organ affected by autoimmune disease via $\mathrm{T}$ cells ${ }^{[1]}$ in which Grave's disease (GD) and Hashimoto's thyroiditis (HT) are common, accompanied with hyperthyroidism or hypothyroidism. AITD is caused by disorders of the thyroidrelated autoimmune system, characterized by lymphocytes infiltration, and the appearance of thyroid autoantibodies. Antithyroid antibodies (ATA) mainly include thyroid peroxidase antibody (TPOAb), thyroglobulin antibody (TgAb), and thyroid-stimulating hormone receptor antibody (TRAb). The appearance of TRAb has a direct role in the pathogenesis of GD, while TPOAb and TgAb are thyroid autoimmunity (TAI) markers, and their production may be a response to thyroid injury.

TRAb may play a role in fetal and neonatal hyperthyroidism. During early pregnancy, high concentrations of human chorionic gonadotropin (hCG) are a high-risk factor for hyperthyroidism, and women with high hCG level often develop transient thyrotoxicosis during gestation. ${ }^{[2-4]}$ Therefore, women at risk are recommended to monitor TRAb titer. ${ }^{[5-9]}$ The presence of positive ATA throughout pregnancy has a higher risk with subclinical hypothyroidism $(\mathrm{SCH})$ and clinical hypothyroidism than those with negative ATA. ${ }^{[10-12]}$ However, about $15 \%-65 \%$ of pregnant women with thyroid-stimulating hormone (TSH) higher than the upper limit of normal range present positive ATA, ${ }^{[13-15]}$ which indicates that there are other causes (such as iodine deficiency, subtotal/total thyroidectomy) that kick in hypothyroidism during pregnancy. Because of the increased risk of hypothyroidism in AITD women during pregnancy, the American Thyroid Association guidelines recommend that women with AITD evaluate TSH concentrations every four weeks in mid-pregnancy. Pregnant women 
with a TSH value of $2.5-10.0 \mathrm{mIU} / \mathrm{L}$ should detect the level of TPOAb, and the level of TSH before entering the ART treatment should not exceed $2.5 \mathrm{mIU} / \mathrm{L}$. This information helps determine which patients should receive interventions. ${ }^{[16]}$

\section{EPIDEMIOLOGY AND DEVELOPMENT IN AITD FEMALE}

The prevalence of AITD in different population usually differs greatly due to differences in age, gender, genetics, environment, iodine intake, ethnicity, etc. A general population survey found that the incidence of AITD was $(11.3 \pm 0.4) \%$, women were much more than men, and the prevalence was positively correlated with aging ${ }^{[17]}$. Positive rates of TPOAb and TgAb in women aged 20-29 were 9.2 and $11.3 \%$, respectively, while those aged 30-39 were 14.5 and $14.2 \%$, respectively. The positive rate of TPOAb in pregnant women is $5 \%-14 \%$, and the positive rate of $\mathrm{TgAb}$ is $3 \%-18 \% \cdot{ }^{[13,18,19]}$ However, due to the differences in analytical methods and diagnostic cutoffs used in each study, there may be differences in the reported thyroid antibody levels and the relationship between antibody levels and pregnancy outcomes. Studies have reported some risk factors for AITD, such as: aging, family history of AITD, iodine deficiency or overdose, and European ancestry, but with no correlation between multiple pregnancies and the occurrence of AITD. ${ }^{[19,20]}$

Studies have shown that the prevalence and titer of thyroid antibodies have decreased during gestation. These studies also reported that the baseline TSH concentration of AITD women was higher than that of antibody-negative women. ${ }^{[10,13,14,21]}$ In women with AITD, the TSH level is maintained at high level during pregnancy. Although the ATA decreases during delivery, the TSH concentration will further increase. The decrease or disappearance of the ATA level during pregnancy may be due to the body's immune tolerance state, which is usually due to gestation. However, the physiological changes that occur during pregnancy lead to an increase in the body's demand for thyroid hormone production, which may counteract the beneficial effects of reduced ATA titers. Although thyroid antibodies can pass through the placenta, TPOAb and TgAb have no effect on fetal thyroid function. ${ }^{[22]}$

\section{AITD MAY INCREASE INFERTILITY HAZARD}

A meta-analysis of four studies showed that among euthyroid women, the risk of unexplained infertility in ATA-positive people is slightly increased (relative risk (RR) $1.47,95 \%$ CI 1.06-2.02). ${ }^{[23]}$ This goal remains to be demonstrated by larger studies. All in all, people understand the relationship between thyroid autoimmunity and infertility because the test data of related studies are substituted, and multiple studies are studied. Therefore, it is not recommended in the American Thyroid Association guideline that positive-ATA females with euthyroidism receive $\mathrm{LT}_{4}$ treatment when trying to conceive normally. ${ }^{[16]}$

Because multiple causes lead to infertility in women with TAI, the pathogenic mechanism between AITD and infertility is unclear. The zona pellucida expresses antigens shared by thyroid tissues, and is, therefore, considered a target for thyroid antibodies. ${ }^{[24]}$ In addition, the Monteleone et al. ${ }^{[25]}$ found that ATA in the follicular fluid of AITD women, and the proportion of these women's fertilization and Grade A embryos, was much lower than that of women without thyroid antibodies. Although, in this study, ATA women had a higher pregnancy success $(43 \%$ vs. $29 \%, P<$ 0.001), without statistical difference. Thus, they speculated that ATA detected in follicles may reduce the quality and fertilization potential of oocytes through antibodymediated cytotoxicity.

\section{AITD may induce a high-risk ART}

Some studies have explored whether AITD will affect the outcome of assisted reproductive technology. The observation objects included in these studies include infertile women caused by different causes. Some of them have completed the first cycle of assisted reproductive assisted pregnancy, and some have received multiple cycles of assisted reproductive assisted pregnancy. It is, therefore, difficult to compare the results of the research. The two main indicators evaluated are usually the proportion of clinically pregnant women and the proportion of miscarried women. Some small-scale studies have reported the correlation between AITD and the low pregnancy rate among women who received assisted reproductive assistance. ${ }^{[26,27]}$ However, most studies have found that there is no significant difference in the pregnancy rate between women with positive thyroid antibody and women with negative antibody among women with normal nail function who received assisted reproductive assist. ${ }^{[28-30]}$

A few studies have discussed the risk of miscarriage after assisted reproductive assisted AITD women with normal nail function, but have obtained the opposite results. Two metaanalysis results showed that women with thyroid antibody positive who received assisted reproductive assist treatment had a significantly increased risk of miscarriage. ${ }^{[31,32]}$ In one of the meta-analysis, ${ }^{[32]} 12$ studies reported that the ratio of miscarriage was 1.44 (95\% CI 1.06-1.95, $P=0.02)$ in AITD women compared with the controls, rather than the baseline TSH concentrations. The analysis found that thyroid antibodies had no effect on the average number of eggs harvested, fertilization, and implantation. 


\section{Intervention in ART cycle of AITD female}

Both the retrospective study and another small-scale randomized controlled trial (RCT) evaluated the therapeutic effect of levothyroxine in euthyroid women with AITD and undergoing ART and infertility treatment. ${ }^{[3,34]}$ Studies in this area have not found any changes in pregnancy or miscarriage among women receiving $\mathrm{LT}_{4}$ treatment. In the study, in addition to aspirin and heparin, the group that received intravenous immunoglobulin, and the other group took only aspirin and heparin, found that the intravenous immunoglobulin group had a higher reproduction rate $(51 \%$ vs. $27 \% ; P=0.027) \cdot{ }^{[35]}$ More small-scale randomized clinical trials have studied the therapeutic effect of glucocorticoids on AITD women and found that the proportion of AITD women taking prednisolone in clinical pregnancy and childbirth is significantly higher than that of AITD women not taking prednisolone. ${ }^{[36,37]}$

Although studies have reported that glucocorticoid therapy is effective, larger studies are still needed to further validate these data. In addition, because it is unknown whether corticosteroids are used early in pregnancy, the use of corticosteroids in early pregnancy requires caution. Although there is still insufficient evidence, but considering that the potential benefit is greater than the minimum risk, the American Thyroid Association guidelines recommend that ATA-positive euthyroid women are better for receive low-dose $\mathrm{LT}_{4}$ supplementation during ART treatment to increase its success. ${ }^{[16]}$

\section{AITD INCREASES THE MISCARRIAGE RISK}

\section{AITD and recurrent miscarriages (RM)}

In 1990, Stagnaro et al. ${ }^{[38]}$ firstly described the relationship between AITD and miscarriage in euthyroid women that the rate of abortion in antibody-positive population was twice those in antibody-negative population $(17.0 \% \mathrm{vs}$. $8.4 \%, P=0.01)$. A meta-analysis involved 12 case-control studies, and 19 prospective cohort studies found that the combined odds ratio (OR) of miscarriage in women with positive thyroid autoantibodies was 1.8 (95\% CI: $1.25-2.60)$ in the case-control studies, and in the cohort studies was 3.9 (95\% CI: 2.48-6.12), which suggests that AITD can definitely increase risk of spontaneous abortion. ${ }^{[39]}$ Relatively, there are still doubts about the correlation between TAI and recurrent miscarriages (RM). Some studies have revealed that AITD may cause multiple abortions, ${ }^{[40,41]}$ while it has not been universally confirmed. ${ }^{[42]}$ A meta-analysis of eight clinical researches found out that, compared with positive-ATA women with normal thyroid function, negative ones have an increased $\mathrm{RM}$ risk $(\mathrm{OR}=$ 2.3, $95 \%$ CI: $1.5-3.5) \cdot{ }^{[23]}$

\section{Pathogenesis of pregnancy loss in AITD female}

Aging is considered as an independent risk factor for spontaneous abortion. ${ }^{[43]}$ Thus, this meta-analysis excluded no age-matched studies and found that the risk of miscarriage in ATA-positive women was higher than that of ATA-negative women. ${ }^{[23]}$ High level of TSH is also considered as a risk factor for miscarriage. ${ }^{[4]}$ Chen et al. ${ }^{[43]}$ included a total of 22 clinical analyses on AITD and miscarriage risk and showed that in euthyroid women, the mean TSH level in ATA-positive patients was 0.61 $\mathrm{mIU} / \mathrm{L}$ higher than that of ATA-negative controls $(P$ $<0.0001)$. Besides, the presence of ATA should be an indirect sign of mild thyroid dysfunction, especially the thyroid abnormal response to increased thyroid hormone demand during pregnancy. A prospective cohort study showed that mild increases in TSH and positive ATA have a superimposed effect on the risk of miscarriage, with normal $\mathrm{FT}_{4}$ and $\mathrm{FT}_{3}$ values, whereas an upper normal range of TSH values in these subjects with RM and AITD. ${ }^{[45]}$ Therefore, it is believed that $\mathrm{LT}_{4}$ supplementation treatment cannot only control the level of TSH but reduce the risk of autoimmune antibodies exposure as well, thereby effectively suppressing the risk of spontaneous miscarriage in such patients. ${ }^{[46]}$

Another potential reason for the increased risk of miscarriage in AITD women is that AITD has comorbidities with other autoimmune diseases, such as systemic lupus erythematosus and antiphospholipid antibody syndrome. There is relationship with AITD and non-organ-specific antibodies. In $\mathrm{RM}$ women, the value of $\mathrm{CD}^{+} / \mathrm{CD}^{+}$ (Th1/Th2 helper cells expressing cytokines) in ATApositive individuals is higher than that in ATA-negative ones, suggesting that the appearance of ATA may be part of systemic immune dysfunction. ${ }^{[47]}$ In women with reproductive failure, the number of $\mathrm{CD}^{+} / \mathrm{CD} 20^{+} \mathrm{B}$ lymphocytes increases significantly, which are involved in the development of autoimmune diseases. ${ }^{[48]}$ It was further found that an immune response dominated by Th1 in cases of RM and embryo transfer (ET) failure. ${ }^{[49]}$ It has been confirmed that INF- $\gamma$, IL- 2 , and TNF- $\alpha$, secreted by Th1 cells, trigger the thrombosis and inflammatory process of maternal uterine placental blood vessels and may directly migrate into the uterus through T lymphocytes or NK cells, thus finally cause miscarriage. ${ }^{[50]}$ All the above-illustrated thyroid autoimmunity maybe non-specific to autoimmune diseases and has an indirect connection with reproductive failure.

By contrast, some hypothesize that ATA plays a direct pathogenic effect on pregnancy failure; $\mathrm{TPOAb}^{+} /$ $\mathrm{TgAb}^{+}$mouse models showed climbing prevalence of fetal absorption, which need further studies to confirm this phenomenon. ${ }^{[51,52]}$ Besides, TRAb is also believed 
to have interaction with hCG receptors, for TRAb may inhibit the $\mathrm{LH} / \mathrm{hCG}$ receptors to reduce the production of progesterone and estrogen, thus lead to miscarriage. ${ }^{[24]}$

\section{Prevention of potential miscarriage in AITD euthyroid women}

The current methods of prevention from miscarriage in AITD women are to supplement levothyroxine or intravenous immunoglobulin. Exogenous supplementation of synthetic thyroid hormone analogs to help to reduce the miscarriage risk in AITD female is based on the consideration of the correlation between AITD and hypothyroidism during pregnancy. RCTs and retrospective observational studies have found that euthyroid pregnant women with AITD received $\mathrm{LT}_{4}$ supplementation has a lower spontaneous abortion than the control group. ${ }^{[53,54]}$ However, there are still doubts whether $\mathrm{LT}_{4}$ treatment has an obvious effect on reproductive success. A randomized study found that supplementation with levothyroxine can reduce the spontaneous abortion rate in $\mathrm{TPOAb}^{+}$women (14.9\% toward $11.6 \%$ ), but without statistical significance. ${ }^{[5]}$ Another RCT on euthyroidism or SCH $(\mathrm{TSH} \leq 10 \mathrm{mIU} / \mathrm{L}$ with normal $\mathrm{FT}_{3}$ and $\mathrm{FT}_{4}$ level) with AITD women also published that $\mathrm{LT}_{4}$ treatment had no protect effect on live birthing (3.6\% of miscarriage rate in treatment $v$ s. $3.4 \%$ in observational control). ${ }^{[21]}$ And, a meta-analysis also reported that insignificant decline in miscarriage rate in ATA-positive euthyroid women who received $\mathrm{LT}_{4}$ treatment. ${ }^{[56]}$ Thus, it is now not clearly recommended or opposed whether ATA-positive women with normal thyroid function need levothyroxine during pregnancy. ${ }^{[16,57]}$ We also need more multi-center clinical randomized trials to further clarify the intervention effect of thyroid hormone on spontaneous abortion, such as TABLET study ${ }^{[58]}$ and T4-LIFE study. ${ }^{[59]}$

In addition, intravenous immunoglobulin is another potential treatment method to suppress the titers. If the pregnancy loss in euthyroid women with ATA is due to the potential systemic autoimmune activation, intravenous immunoglobulin may effectively regulate the cellular response of transformation of Th1 to Th2 and eventually avoid abortion in these population. ${ }^{[60]}$ Unfortunately, this method has application limits. ${ }^{[61,62]}$ One of the clinical trials observed and compared the livebirth rate of $\mathrm{LT}_{4}$ supplementation and intravenous immunoglobulin for ATA-positive female and found out that the delivery outcomes in those with $\mathrm{LT}_{4}$ supplementation were generally improved than those with immunoglobulin injections. ${ }^{[62]}$ Due to lack of sufficient evidence, it is not recommended for RM women with TAI and euthyroidism to undergo $\mathrm{LT}_{4}$ treatment. ${ }^{[16]}$

\section{AITD MAY INCREASE THE RISK OF PREMATURE DELIVERY (PTD)}

The incidence of preterm birth is $6 \%-10 \%$ in China, in which induced abortion (44.6\%), premature rupture of the membranes (PPROM, 44.2\%), and unknown reasons $(21.0 \%)$ are the main causes of preterm birth. ${ }^{[63]}$ In 1994 , Glinoer ${ }^{[10]}$ discovered that women with AITD had a doubling premature delivery (PTD) rate $(16 \%$ in AITD vs. $8 \%$ in controls, $P<0.005)$. A meta-analysis of five cohort studies confirmed that the appearance of ATA was clearly related to the PTD risk (OR $=2.07,95 \%$ CI: $1.17-3.68$, $P=0.01) \cdot{ }^{[39]}$ Another meta-analysis of 11 prospective cohort studies showed that the overall RR of preterm birth in euthyroid women with AITD was 1.98 (95\% CI 1.29-3.04, $P=0.002) .{ }^{[64]}$ At present, the pathophysiological mechanism of the correlation between TAI and premature birth is not clear, slight damage to thyroid function, direct action of ATA, systemic non-specific autoimmune hyperactivity, or all of the above reasons may have played roles in PTD. ${ }^{[65]}$

\section{Management of PTD risk in AITD euthyroid women throughout pregnancy}

Some randomized clinical trials have found that PTD risk in ATA-positive female can be reduced via levothyroxine supplementation, ${ }^{[21,66]}$ in which Nazarpour et al. ${ }^{[21]}$ reported reducing of preterm delivery, however, mainly present in $\mathrm{TPOAb}^{+}$women with TSH over $4 \mu \mathrm{IU} / \mathrm{ml}$. Meanwhile, the impact of $\mathrm{LT}_{4}$ treatment in preterm delivery rates in another $\mathrm{RCT}^{[55]}$ revealed no beneficial effect. In this trial, the enrolled women with $\mathrm{TPOAb}^{+}$and TSH less than 2.5 $\mathrm{mIU} / \mathrm{L}$ were randomly selected to treatment group, $\mathrm{LT}_{4}$ replacement as $0.5 \mu \mathrm{g} /(\mathrm{kg} \cdot \mathrm{d})$ for pregnant women with TSH between 0.5 and $1.5 \mathrm{mIU} / \mathrm{L}$ and $1.0 \mu \mathrm{g} /(\mathrm{kg} \cdot \mathrm{d})$ for those at $1.5-2.5 \mathrm{mIU} / \mathrm{L}$, and control group untreated in the first trimester of pregnancy and received $\mathrm{LT}_{4}$ intervention if TSH exceeded $3.0 \mathrm{mIU} / \mathrm{L}$ from the second trimester. In conclusion, the present studies are insufficient to prove that levothyroxine intervention has an impact on the PTD rate in euthyroid thyroid antibody-positive women. ${ }^{[16]}$

\section{WOMEN WITH AITD MAY BE AT INCREASED RISK OF OTHER ADVERSE PREGNANCY AND DEVELOPMENTAL OUTCOMES}

\section{TAI impact on other adverse neonatal outcomes}

Current controversies are focused on the relationship between maternal TAI and fetal neurodevelopmental disorders. ${ }^{[67-70]}$ Wasserman et al..$^{[71]}$ found that the motherto-be with $\mathrm{TPOAb}^{+}$in the third trimester eventually gave 
birth to lower IQ score, in which the gap peaked in the IQ scores at the aged of four, and then narrowed after the age of seven. Furthermore, sensorineural hearing loss turned out to be related to intelligence, with an OR of 7.5 in risk of sensorineural hearing loss in children whose mothers occurred gestational AITD (95\% CI: $2.4-23.3) \cdot .^{[72]}$ Hence, it remains to be further studied whether the development of the fetal nervous system is interacted with maternal TAI, gestational $\mathrm{SCH}$, or direct systemic autoimmune disorders, or both.

It is reported that mothers who were $\mathrm{TPOAb}^{+}$more often had intrauterine growth retardation (IUGR) infants than TPOAb mothers and thus might lead to the climbing incidence of PTD, ${ }^{[73]}$ while the correlation has not been confirmed generally by evidence-based medicine. ${ }^{74]}$ Besides, the offspring of ATA-positive mothers had threefold greater perinatal mortality than those of ATAnegative, ${ }^{[7]}$ but this conclusion has not been generally accepted. ${ }^{[20,75]}$ On the other hand, Negro et al. ${ }^{[75]}$ found an increase in respiratory distress in infants due to their mothers with ATA-positive during pregnancy. In short, these present studies provide suggestive evidence of an association between TAI and adverse newborns outcomes in euthyroid women, which should be considered preliminary and awaits further studies.

\section{TAI and other complications of pregnancy}

Some clinical studies have found that postpartum depression (PPD) is related to AITD. However, the mechanism underlying this relationship is unclear. ${ }^{[76]}$ An established isolated TPOAb-positive mouse model displayed depressive behaviors and a decrease of the concentration of brain-derived neurotrophic factor (BDNF) and 5-HT in the prefrontal cortex without changes in the total $\mathrm{T}_{4}$ concentration in the prefrontal cortex. So, they hypothesized that the presence of ATA inhibited 5-HT-BDNF interactions and regulated the process of neural remodeling, clinically caused cognition impairment and social misbehavior. ${ }^{[77]}$ Other hypotheses were proposed that a surge of pro-inflammatory cytokines in autoimmune diseases induces depression. ${ }^{[78]}$

Ying's study ${ }^{[79]}$ has found that $\mathrm{TPOAb}^{+}$euthyroidism in early pregnancy is associated with an increased risk of gestational diabetes mellitus, but meta-analysis did not show this association clearly. ${ }^{[80]}$ In addition, the most common complications of late pregnancy in AITD patients are abruptio placentae (AP) and PPROM. Compared with TPOAb ${ }^{-}$pregnancies, the $\mathrm{TPOAb}^{+}$ones suffered from an increased AP risk. ${ }^{[20]}$ The FaSTER trial ${ }^{[81]}$ further found $\mathrm{TPOAb}^{+}$women in the first and second trimesters have a higher AP hazard than TPOAb women. And, a similar but weaker relationship was present for $\mathrm{TgAb}$. However,
ORs for pregnancies with both TPOAb+ and $\mathrm{TgAb}+$ were much higher (first trimester: 2.10, 95\% CI 0.91-4.86; second trimester: 2.73 , 95\% CI 1.17-6.33).

\section{CONCLUSIONS}

The interaction between autoimmune thyroid diseases and complications of fertility and pregnancy is complex. Thyroid autoimmunity and following overt thyroid dysfunction lead to infertility and pregnancy and neonatal complications. Thus, it seems reasonable to screen for TSH concentrations and thyroid antibodies (including TPOAb and $\mathrm{TgAb}$ ) in infertile women attempting spontaneous or assisted conception. Based on the existing literature, at present, there is insufficient evidence for the beneficial outcomes of antibody titer suppression and hormone supplementation. Considering the possible adverse effects of overtreatment, it is more cautious in particular in patients with ATA-positive and euthyoridism to receive low-dose $\mathrm{LT}_{4}$ treatment accordingly during conception and pregnancy. In summary, it is now not clearly recommended or opposed whether ATA-positive women with normal thyroid function need levothyroxine during pregnancy, and it is necessary to conduct more investigations to raise our awareness of this issue.

\section{Declarations}

Not applicable

\section{Conflicts of Interests}

The authors have no conflicts of interest to disclose.

\section{Source of Foundation}

This work was supported by Nantong Municipal Commission of Health and Family Planning (QA2019037), National Natural Science Foundation of China (81500447), and General Financial Grant from the China Postdoctoral Science Foundation (2015 M572742).

\section{Authors' Contributions}

Li T contributes in study design and critical discussion. Wang JW contributes in manuscript drafting and critical discussion. Li XX contributes in study design and execution. All authors read and approved the final manuscript.

\section{REFERENCES}

1. Orgiazzi J. Thyroid autoimmunity. Presse Med 2012; 41: e611-25.

2. Cooper DS, Laurberg P. Hyperthyroidism in pregnancy. Lancet Diabetes Endocrinol 2013; 1: 238-49. 
3. Bucci I, Giuliani C, Napolitano G. Thyroid-Stimulating Hormone Receptor Antibodies in Pregnancy: Clinical Relevance. Front Endocrinol (Lausanne) 2017; 8: 137.

4. Korevaar TI, de Rijke YB, Chaker L, Medici M, Jaddoe VM, Steegers EA, et al. Stimulation of Thyroid Function by Human Chorionic Gonadotropin During Pregnancy: A Risk Factor for Thyroid Disease and a Mechanism for Known Risk Factors. Thyroid 2017; 27: 440-50.

5. Kahaly GJ, Diana T. TSH Receptor Antibody Functionality and Nomenclature. Front Endocrinol (Lausanne) 2017; 8: 28.

6. Barbesino G, Tomer Y. Clinical review: Clinical utility of TSH receptor antibodies. J Clin Endocrinol Metab 2013; 98: 2247-55.

7. Abeillon-du Payrat J, Chikh K, Bossard N, Bretones P, Gaucherand P, Claris $\mathrm{O}$, et al. Predictive value of maternal second-generation thyroidbinding inhibitory immunoglobulin assay for neonatal autoimmune hyperthyroidism. Eur J Endocrinol 2014; 171: 451-60.

8. McLachlan SM, Rapoport B. Thyrotropin-blocking autoantibodies and thyroid-stimulating autoantibodies: potential mechanisms involved in the pendulum swinging from hypothyroidism to hyperthyroidism or vice versa. Thyroid 2013; 23: 14-24.

9. Skuza KA, Sills IN, Stene M, Rapaport R. Prediction of neonatal hyperthyroidism in infants born to mothers with Graves disease. J Pediatr 1996; 128: 264-8.

10. Glinoer D, Riahi M, Grun JP, Kinthaert J. Risk of subclinical hypothyroidism in pregnant women with asymptomatic autoimmune thyroid disorders. J Clin Endocrinol Metab 1994; 79: 197-204.

11. Pearce EN, Oken E, Gillman MW, Lee SL, Magnani B, Platek D, et al. Association of first-trimester thyroid function test values with thyroperoxidase antibody status, smoking, and multivitamin use. Endocr Pract 2008; 14: 33-9.

12. Medici M, de Rijke YB, Peeters RP, Visser W, de Muinck Keizer-Schrama SW, Jaddoe VV, et al. Maternal early pregnancy and newborn thyroid hormone parameters: the Generation R study. J Clin Endocrinol Metab 2012; 97: 646-52.

13. Moreno-Reyes R, Glinoer D, Van Oyen H, Vandevijvere S. High prevalence of thyroid disorders in pregnant women in a mildly iodinedeficient country: a population-based study. J Clin Endocrinol Metab 2013; 98: 3694-701.

14. Feki M, Omar S, Menif O, Tanfous NB, Slimane H, Zouari F, et al. Thyroid disorders in pregnancy: frequency and association with selected diseases and obstetrical complications in Tunisian women. Clin Biochem 2008; 41: 927-31.

15. Blatt AJ, Nakamoto JM, Kaufman HK. National status of testing for hypothyroidism during pregnancy and postpartum. J Clin Endocrinol Metab 2012; 97: 777-84.

16. Alexander EK, Pearce EN, Brent GA, Brown RS, Chen H, Dosiou C, et al. 2017 Guidelines of the American Thyroid Association for the Diagnosis and Management of Thyroid Disease During Pregnancy and the Postpartum. Thyroid 2017; 27: 315-89.

17. Hollowell JG, Staehling NW, Flanders WD, Hannon WH, Gunter EW, Spencer CA, et al. Serum TSH, T(4), and thyroid antibodies in the United States population (1988 to 1994): National Health and Nutrition Examination Survey (NHANES III). J Clin Endocrinol Metab, 2002; 87: 489-99.

18. Ashoor G, Maiz N, Rotas M, Jawdat F, Nicolaides KH. Maternal thyroid function at 11 to 13 weeks of gestation and subsequent fetal death. Thyroid 2010; 20: 989-93.

19. Shi X, Han C, Li C, Mao J, Wang W, Xie X, et al. Optimal and safe upper limits of iodine intake for early pregnancy in iodine-sufficient regions: a cross-sectional study of 7190 pregnant women in China. J Clin Endocrinol Metab 2015; 100: 1630-8.

20. Abbassi-Ghanavati M, Casey BM, Spong CY, McIntire DD, Halvorson LM, Cunningham FG. Pregnancy outcomes in women with thyroid peroxidase antibodies. Obstet Gynecol 2010; 116: 381-6.

21. Nazarpour S, Ramezani Tehrani F, Simbar M, Tohidi M, Alavi Majd H, Azizi F. Effects of levothyroxine treatment on pregnancy outcomes in pregnant women with autoimmune thyroid disease. Eur J Endocrinol 2017; 176: 253-65.

22. Dussault JH, Letarte J, Guyda H, Laberge C. Lack of influence of thyroid antibodies on thyroid function in the newborn infant and on a mass screening program for congenital hypothyroidism. J Pediatr 1980; 96: 385-9.

23. van den Boogaard E, Vissenberg R, Land JA, van Wely M, van der Post JA, Goddijn M, et al. Significance of (sub)clinical thyroid dysfunction and thyroid autoimmunity before conception and in early pregnancy: a systematic review. Hum Reprod Update 2011; 17: 605-19.

24. Twig G, Shina A, Amital H, Shoenfeld Y. Pathogenesis of infertility and recurrent pregnancy loss in thyroid autoimmunity. J Autoimmun 2012; 38: J275-81.

25. Monteleone P, Parrini D, Faviana P, Carletti E, Casarosa E, Uccelli A, et al. Female infertility related to thyroid autoimmunity: the ovarian follicle hypothesis. Am J Reprod Immunol 2011; 66: 108-14.

26. Geva E, Vardinon N, Lessing JB, Lerner-Geva L, Azem F, Yovel I, et al. Organ-specific autoantibodies are possible markers for reproductive failure: a prospective study in an in-vitro fertilization-embryo transfer programme. Hum Reprod 1996; 11: 1627-31.

27. Zhong YP, Ying Y, Wu HT, Zhou CQ, Xu YW, Wang Q, et al. Relationship between antithyroid antibody and pregnancy outcome following in vitro fertilization and embryo transfer. Int J Med Sci 2012; 9: 121-5.

28. Lukaszuk K, Kunicki M, Kulwikowska P, Liss J, Pastuszek E, Jaszczolt M, et al. The impact of the presence of antithyroid antibodies on pregnancy outcome following intracytoplasmatic sperm injection-ICSI and embryo transfer in women with normal thyreotropine levels. J Endocrinol Invest 2015; 38: 1335-43.

29. Unuane D, Velkeniers B, Bravenboer B, Drakopoulos P, Tournaye H, Parra J, et al. Impact of thyroid autoimmunity in euthyroid women on live birth rate after IUI. Hum Reprod 2017; 32: 915-22.

30. Sakar MN, Unal A, Atay AE, Zebitay AG, Verit FF, Demir S, et al. Is there an effect of thyroid autoimmunity on the outcomes of assisted reproduction? J Obstet Gynaecol 2016; 36: 213-7.

31. Toulis KA, Goulis DG, Venetis CA, Kolibianakis EM, Negro R, Tarlatzis $\mathrm{BC}$, et al. Risk of spontaneous miscarriage in euthyroid women with thyroid autoimmunity undergoing IVF: a meta-analysis. Eur J Endocrinol 2010; 162: 643-52.

32. Busnelli A, Paffoni A, Fedele L, Somigliana E. The impact of thyroid autoimmunity on IVF/ICSI outcome: a systematic review and metaanalysis. Hum Reprod Update 2016; 22: 775-90.

33. Revelli A, Casano S, Piane LD, Grassi G, Gennarelli G, Guidetti D, et al. A retrospective study on IVF outcome in euthyroid patients with antithyroid antibodies: effects of levothyroxine, acetyl-salicylic acid and prednisolone adjuvant treatments. Reprod Biol Endocrinol 2009; 7: 137.

34. Negro R, Mangieri T, Coppola L, Presicce G, Casavola EC, Gismondi R, et al. Levothyroxine treatment in thyroid peroxidase antibody-positive women undergoing assisted reproduction technologies: a prospective study. Hum Reprod 2005; 20: 1529-33.

35. Sher G, Maassarani G, Zouves C, Feinman M, Sohn S, Matzner W, et al. The use of combined heparin/aspirin and immunoglobulin $\mathrm{G}$ therapy in the treatment of in vitro fertilization patients with antithyroid antibodies. Am J Reprod Immunol 1998; 39: 223-5.

36. Turi A, Giannubilo SR, Zanconi S, Mascetti A, Tranquilli AL. Preconception steroid treatment in infertile women with antithyroid autoimmunity undergoing ovarian stimulation and intrauterine insemination: a double-blind, randomized, prospective cohort study. Clin Ther 2010; 32: 2415-21.

37. Litwicka K, Arrivi C, Varricchio MT, Mencacci C, Greco E. In women with thyroid autoimmunity, does low-dose prednisolone administration, compared with no adjuvant therapy, improve in vitro fertilization clinical results? J Obstet Gynaecol Res 2015; 41: 722-8.

38. Stagnaro-Green A, Roman SH, Cobin RH, el-Harazy E, Alvarez-Marfany $\mathrm{M}$, Davies TF. Detection of at-risk pregnancy by means of highly sensitive assays for thyroid autoantibodies. JAMA 1990; 264: 1422-5. 
39. Thangaratinam S, Tan A, Knox E, Kilby MD, Franklyn J, Coomarasamy A. Association between thyroid autoantibodies and miscarriage and preterm birth: meta-analysis of evidence. BMJ 2011; 342: d2616.

40. Iravani AT, Saeedi MM, Pakravesh J, Hamidi S, Abbasi M. Thyroid autoimmunity and recurrent spontaneous abortion in Iran: a case-control study. Endocr Pract 2008; 14: 458-64.

41. Lata K, Dutta P, Sridhar S, Rohilla M, Srinivasan A, Prashad GR, et al. Thyroid autoimmunity and obstetric outcomes in women with recurrent miscarriage: a case-control study. Endocr Connect 2013; 2: 118-24.

42. Rushworth FH, Backos M, Rai R, Chilcott IT, Baxter N, Regan L. Prospective pregnancy outcome in untreated recurrent miscarriers with thyroid autoantibodies. Hum Reprod 2000; 15: 1637-9.

43. Chen L, Hu R. Thyroid autoimmunity and miscarriage: a meta-analysis. Clin Endocrinol (Oxf) 2011; 74: 513-9.

44. Plowden TC, Schisterman EF, Sjaarda LA, Mumford SL. Response to Letter: Are We Really Sure that Subclinical Hypothyroidism and Thyroid Autoimmunity Are Not Associated With Fecundity, Pregnancy Loss, or Live Birth? J Clin Endocrinol Metab 2016; 101: L87-8.

45. Lazzarin N, Moretti C, De Felice G, Vaquero E, Manfellotto D. Further evidence on the role of thyroid autoimmunity in women with recurrent miscarriage. Int J Endocrinol 2012; 2012: 717185.

46. Liu H, Shan Z, Li C, Mao J, Xie X, Wang W, et al. Maternal subclinical hypothyroidism, thyroid autoimmunity, and the risk of miscarriage: a prospective cohort study. Thyroid 2014; 24: 1642-9.

47. Kim NY, Cho HJ, Kim HY, Yang KM, Ahn HK, Thornton S, et al. Thyroid autoimmunity and its association with cellular and humoral immunity in women with reproductive failures. Am J Reprod Immunol 2011; 65: 78-87.

48. Roberts J, Jenkins C, Wilson R, Pearson C, Franklin IA, MacLean MA, et al. Recurrent miscarriage is associated with increased numbers of CD5/20 positive lymphocytes and an increased incidence of thyroid antibodies. Eur J Endocrinol 1996; 134: 84-6.

49. Kwak-Kim JY, Chung-Bang HS, Ng SC, Ntrivalas EI, Mangubat CP, Beaman KD, et al. Increased Thelper 1 cytokine responses by circulating $\mathrm{T}$ cells are present in women with recurrent pregnancy losses and in infertile women with multiple implantation failures after IVF. Hum Reprod 2003; 18: 767-73.

50. Konova E. The role of NK cells in the autoimmune thyroid diseaseassociated pregnancy loss. Clin Rev Allergy Immunol 2010; 39: 176-84.

51. Lee YL, Ng HP, Lau KS, Liu WM, O WS, Yeung WS, et al. Increased fetal abortion rate in autoimmune thyroid disease is related to circulating TPO autoantibodies in an autoimmune thyroiditis animal model. Fertil Steril 2009; 91: 2104-9.

52. Matalon ST, Blank M, Levy Y, Carp HJ, Arad A, Burek L, et al. The pathogenic role of anti-thyroglobulin antibody on pregnancy: evidence from an active immunization model in mice. Hum Reprod 2003; 18: 1094-9.

53. Lepoutre T, Debieve F, Gruson D, Daumerie C. Reduction of miscarriages through universal screening and treatment of thyroid autoimmune diseases. Gynecol Obstet Invest 2012; 74: 265-73.

54. Vissenberg R, Fliers E, van der Post JA, van Wely M, Bisschop PH, Goddijn M. Live-birth rate in euthyroid women with recurrent miscarriage and thyroid peroxidase antibodies. Gynecol Endocrinol 2016; 32: 132-5.

55. Negro R, Schwartz A, Stagnaro-Green A. Impact of Levothyroxine in Miscarriage and Preterm Delivery Rates in First Trimester Thyroid Antibody-Positive Women With TSH Less Than $2.5 \mathrm{mIU} / \mathrm{L}$. J Clin Endocrinol Metab 2016; 101: 3685-90.

56. Vissenberg R, van den Boogaard E, van Wely M, van der Post JA, Fliers E, Bisschop PH, et al. Treatment of thyroid disorders before conception and in early pregnancy: a systematic review. Hum Reprod Update 2012; 18: $360-73$.

57. De Groot, L., M. Abalovich, E.K. Alexander, N. Amino, L. Barbour, R.H. Cobin, et al., Management of thyroid dysfunction during pregnancy and postpartum: an Endocrine Society clinical practice guideline. J Clin Endocrinol Metab 2012; 97: 2543-65.

58. Dhillon-Smith RK, Middleton LJ, Sunner KK, Cheed V, Baker K, FarrellCarver S, et al. Levothyroxine in Women with Thyroid Peroxidase Antibodies before Conception. N Engl J Med 2019; 380: 1316-25.

59. Vissenberg R, van Dijk MM, Fliers E, van der Post JAM, van Wely M, Bloemenkamp KWM, et al. Effect of levothyroxine on live birth rate in euthyroid women with recurrent miscarriage and TPO antibodies (T4LIFE study). Contemp Clin Trials 2015; 44: 134-8.

60. Yamada H, Morikawa M, Furuta I, Kato EH, Shimada S, Iwabuchi K, et al. Intravenous immunoglobulin treatment in women with recurrent abortions: increased cytokine levels and reduced Th1/Th2 lymphocyte ratio in peripheral blood. Am J Reprod Immunol 2003; 49: 84-9.

61. Stricker RB, Steinleitner A, Bookoff CN, Weckstein LN, Winger EE. Successful treatment of immunologic abortion with low-dose intravenous immunoglobulin. Fertil Steril 2000; 73: 536-40.

62. Vaquero E, Lazzarin N, De Carolis C, Valensise H, Moretti C, Ramanini C. Mild thyroid abnormalities and recurrent spontaneous abortion: diagnostic and therapeutical approach. Am J Reprod Immunol 2000; 43: 204-8.

63. Zou L, Wang X, Ruan Y, Li G, Chen Y, Zhang W. Preterm birth and neonatal mortality in China in 2011. Int J Gynaecol Obstet 2014; 127: 243-7.

64. He X, Wang P, Wang Z, He X, Xu D, Wang B. Thyroid antibodies and risk of preterm delivery: a meta-analysis of prospective cohort studies. Eur J Endocrinol 2012; 167: 455-64.

65. Korevaar TI, Steegers EA, Pop VJ, Broeren MA, Chaker L, de Rijke YB, et al. Thyroid Autoimmunity Impairs the Thyroidal Response to Human Chorionic Gonadotropin: Two Population-Based Prospective Cohort Studies. J Clin Endocrinol Metab 2017; 102: 69-77.

66. Negro R, Formoso G, Mangieri T, Pezzarossa A, Dazzi D, Hassan H. Levothyroxine treatment in euthyroid pregnant women with autoimmune thyroid disease: effects on obstetrical complications. J Clin Endocrinol Metab 2006; 91: 2587-91.

67. Pop VJ, de Vries E, van Baar AL, Waelkens JJ, de Rooy HA, Horsten $\mathrm{M}$, et al. Maternal thyroid peroxidase antibodies during pregnancy: a marker of impaired child development? J Clin Endocrinol Metab 1995; 80: 3561-6.

68. Li Y, Shan Z, Teng W, Yu X, Li Y, Fan C, et al. Abnormalities of maternal thyroid function during pregnancy affect neuropsychological development of their children at 25-30 months. Clin Endocrinol (Oxf) 2010; 72: 825-9.

69. Williams FL, Watson J, Ogston SA, Visser TJ, Hume R, Willatts P. Maternal and umbilical cord levels of T4, FT4, TSH, TPOAb, and TgAb in term infants and neurodevelopmental outcome at 5.5 years. J Clin Endocrinol Metab 2013; 98: 829-38.

70. Ghassabian A, Bongers-Schokking JJ, de Rijke YB, van Mil N, Jaddoe VW, de Muinck Keizer-Schrama SM, et al. Maternal thyroid autoimmunity during pregnancy and the risk of attention deficit/hyperactivity problems in children: the Generation R Study. Thyroid 2012; 22: 178-86.

71. Wasserman EE, Pillion JP, Duggan A, Nelson K, Rohde C, Seaberg EC, et al. Childhood IQ, hearing loss, and maternal thyroid autoimmunity in the Baltimore Collaborative Perinatal Project. Pediatr Res 2012; 72: 525-30.

72. Wasserman EE, Nelson K, Rose NR, Eaton W, Pillion JP, Seaberg E, et al. Maternal thyroid autoantibodies during the third trimester and hearing deficits in children: an epidemiologic assessment. Am J Epidemiol 2008; 167: 701-10.

73. Mannisto T, Vaarasmaki M, Pouta A, Hartikainen AL, Ruokonen A, Surcel HM, et al. Perinatal outcome of children born to mothers with thyroid dysfunction or antibodies: a prospective population-based cohort study. J Clin Endocrinol Metab 2009; 94: 772-9.

74. Tong Z, Xiaowen Z, Baomin C, Aihua L, Yingying Z, Weiping Z, et al. The Effect of Subclinical Maternal Thyroid Dysfunction and Autoimmunity 
on Intrauterine Growth Restriction: A Systematic Review and MetaAnalysis. Medicine (Baltimore) 2016; 95: e3677.

75. Negro R, Schwartz A, Gismondi R, Tinelli A, Mangieri T, Stagnaro-Green A. Thyroid antibody positivity in the first trimester of pregnancy is associated with negative pregnancy outcomes. J Clin Endocrinol Metab 2011; 96: E920-4.

76. Dama M, Steiner M, Lieshout RV. Thyroid peroxidase autoantibodies and perinatal depression risk: A systematic review. J Affect Disord 2016; 198: 108-21.

77. Zhou Y, Wang X, Zhao Y, Liu A, Zhao T, Zhang Y, et al. Elevated Thyroid Peroxidase Antibody Increases Risk of Post-partum Depression by Decreasing Prefrontal Cortex BDNF and 5-HT Levels in Mice. Front
Cell Neurosci 2016; 10: 307.

78. Postal M, Appenzeller S. The importance of cytokines and autoantibodies in depression. Autoimmun Rev 2015; 14: 30-5.

79. Ying H, Tang YP, Bao YR, Su XJ, Cai X, Li YH, et al. Maternal TSH level and TPOAb status in early pregnancy and their relationship to the risk of gestational diabetes mellitus. Endocrine 2016; 54: 742-50.

80. Yang Y, Li Q, Wang Q, Ma X. Thyroid antibodies and gestational diabetes mellitus: a meta-analysis. Fertil Steril 2015; 104: 665-71 e3.

81. Haddow JE, McClain MR, Palomaki GE, Neveux LM, LambertMesserlian G, Canick JA, et al.Thyroperoxidase and thyroglobulin antibodies in early pregnancy and placental abruption. Obstet Gynecol 2011; 117: 287-92.

How to cite this article: Wang JW, Liao XX, Li T. Thyroid autoimmunity in adverse fertility and pregnancy outcomes: Timing of assisted reproductive technology in AITD women. J Transl Intern Med 2021; 9: 76-83. 